\title{
Robotic general surgery: current practice, evidence, and perspective
}

\author{
M. Jung • P. Morel • L. Buehler • N. C. Buchs • \\ M. E. Hagen
}

Received: 21 January 2015 / Accepted: 27 January 2015 /Published online: 18 February 2015

(C) Springer-Verlag Berlin Heidelberg 2015

\begin{abstract}
Background Robotic technology commenced to be adopted for the field of general surgery in the 1990s. Since then, the da Vinci surgical system (Intuitive Surgical Inc, Sunnyvale, CA, USA) has remained by far the most commonly used system in this domain. The da Vinci surgical system is a master-slave machine that offers three-dimensional vision, articulated instruments with seven degrees of freedom, and additional software features such as motion scaling and tremor filtration. The specific design allows hand-eye alignment with intuitive control of the minimally invasive instruments. As such, robotic surgery appears technologically superior when compared with laparoscopy by overcoming some of the technical limitations that are imposed on the surgeon by the conventional approach.

Purpose This article reviews the current literature and the perspective of robotic general surgery.

Conclusions While robotics has been applied to a wide range of general surgery procedures, its precise role in this field remains a subject of further research. Until now, only limited clinical evidence that could establish the use of robotics as the gold standard for procedures of general surgery has been created. While surgical robotics is still in its infancy with multiple novel systems currently under development and clinical trials in progress, the opportunities for this technology appear endless, and robotics should have a lasting impact to the field of general surgery.
\end{abstract}

M. Jung $\cdot$ P. Morel $\cdot$ L. Buehler $\cdot$ N. C. Buchs $\cdot$ M. E. Hagen $(\varangle)$ Division of Digestive and Transplant Surgery, Department of Surgery, University Hospital Geneva, 4 Rue Gabrielle-Perret-Gentil, 1211 Geneva, Switzerland

e-mail: monikahagen@aol.com
Keywords Robotic surgery · General surgery $\cdot$ da Vinci · Robotics

\section{Introduction}

Surgery has traditionally been an arena with a strong surge for improvements to the benefits of many patients. Several milestones in the history of surgery revolutionized the treatment, including the discovery of asepsis, the development of modern anesthesia, and many others including the invention of laparoscopy. While these major quantum leaps appear genius in retrospect, they were often the subject of debate and sometimes even disdain in their time. As such, Kurt Semm, who performed the first laparoscopic appendectomy in Germany in 1981, was at risk to have his medical license revoked for his work in the development of minimally invasive surgery $[1,2]$. In the years to follow, laparoscopy was progressively adapted for many general surgery procedures as it became evident that peri-operative patient outcomes could be improved using minimally invasive approaches. As a further progression in advancing minimally invasive surgery beyond manual laparoscopy, early developments of robotic for general surgery commenced in the 1980s with trans-disciplinary collaborations in the Silicon Valley. During that time, the National Aeronautics and Space Administration Ames Research Group developed a head-mounted display which was originally meant to transmit large amount of data from space missions to co-coordinators on the ground [3]. Around the same time, VPL Inc. developed the DataGlove - a wired glove that allowed physical interaction with virtual scenes. The liaison of these two innovators combined with the robotic expertise of the former Stanford Research Institute gave birth to a first robotic system that was suitable for applications in minimally invasive general 
surgery. Further refinements of the system lead to the development of the da Vinci surgical system that was commercialized by Intuitive Surgical Inc. (Sunnyvale, CA, USA). Since the first clinical application in 1998 with a pre-market prototype called Mona, the da Vinci standard system developed over the S and Si system to the latest launched product, the da Vinci Xi (Fig. 1), which was released in 2014 (http://www. intuitivesurgical.com/products/) [4]. Over the years, the da Vinci system family has been used for an increasing amount of procedures from many fields of surgery [5-7]. Adoption was mainly driven by the continuous surge to improve clinical outcomes by overcoming technical limitations of conventional laparoscopy as the da Vinci surgical systems dispose of a variety of technical specifications including:

- physical separation between patient and surgeon with computer interface

- true three-dimensional vision with up to ten times magnification

- endo-wristed instruments (Fig. 2) with seven degrees of freedom

- software features including motion scaling and tremor filtration

- strong hand-eye alignment resulting in intuitive control of instrumentation by the surgeon

- computer interface in between the patient and the surgeon

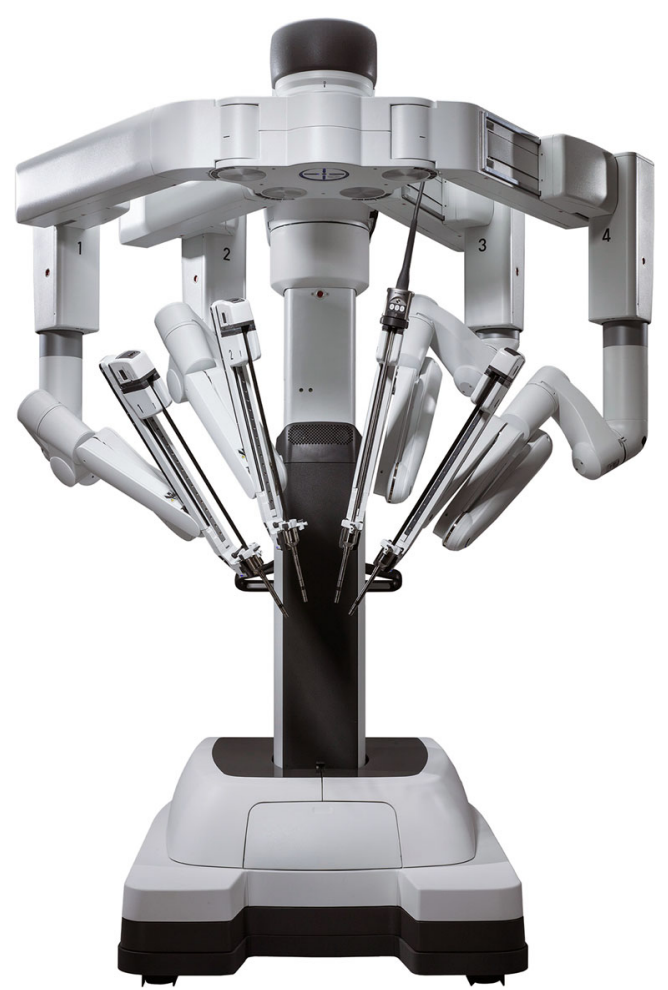

Fig. 1 Robotics arms of the da Vinci Xi system (courtesy of Intuitive Surgical Inc.)

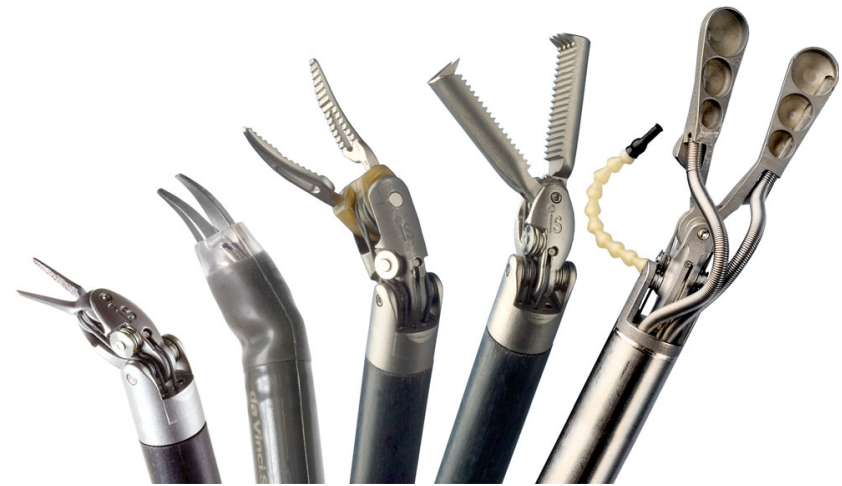

Fig. 2 da Vinci wristed instruments (courtesy of Intuitive Surgical Inc.)

As such, it is evident that the technical specifications far exceed the ones of conventional laparoscopy, and it can be assumed that the robotic system is capable of overcoming some of the limitations of a conventional laparoscopic approach. While laparoscopy has become the gold standard for a variety of rather easy general surgery procedures, the penetration for advanced surgeries of advanced complexity which might either be derived by space constraints or technical demands has been limited [8-10]. Exactly in these surgical spaces, the da Vinci surgical system appears as a potential "enabler" of minimally invasive surgery by overcoming the technical limitations of conventional laparoscopy. As such, while laparoscopic radical prostatectomy is a very challenging and rarely performed procedure, the robotic approach has been established as the gold standard for the removal of prostate cancer [11]. The value of robotics for this procedure has been clearly established by high-level-of-evidence studies, including prospectively randomized trials and high quality meta-analyses [12-14]. As a result, robotics for radical prostatectomy received positive evaluations by several health technology assessments and is the recommended surgical method by clinical guidelines [11].

While the role of robotics for radical prostatectomy appears clear, the application in the field of general surgery is less evident, and it requires careful analysis whether the aspirational value of the doubtless superior technology reliably results in improved patient outcomes ultimately leading to clinical and cost effectiveness. As such, this manuscript aims to review the current practice, evidence, and perspective of robotic general surgery.

\section{Clinical applications of robotics in general surgery}

Please refer to Table 1 for a list of prospectively randomized trial of robotic general surgery. 
Table 1 Randomized controlled trials comparing robotic surgery to alternative approach

\begin{tabular}{|c|c|c|c|c|}
\hline Authors & Procedure & Comparator & $\begin{array}{l}\text { No of subjects } \\
\text { (robotic/comparator) }\end{array}$ & Key outcomes \\
\hline Mueller-Stich et al. [15] & Fundoplication & Laparoscopy & $20 / 20$ & $\begin{array}{l}\text { Robotic with shorter OR time, higher costs. } \\
\text { Similar short-term outcome }\end{array}$ \\
\hline Draaisma et al. [16] & Fundoplication & Laparoscopy & $25 / 25$ & Similar outcomes of all parameters \\
\hline Morino et al. [17] & Fundoplication & Laparoscopy & $25 / 25$ & $\begin{array}{l}\text { Similar outcomes of all clinical parameters. } \\
\text { Higher costs for robotics }\end{array}$ \\
\hline Nakadi et al. [18] & Fundoplication & Laparoscopy & $9 / 11$ & $\begin{array}{l}\text { Similar outcomes of all clinical parameters, } \\
\text { longer OR times, and higher costs for robotics }\end{array}$ \\
\hline Sanchez et al. [19] & Gastric Bypass & Laparoscopy & $25 / 25$ & $\begin{array}{l}\text { Shorter OR times for robotics during learning } \\
\text { curve, decrease maximized with larger BMIs }\end{array}$ \\
\hline Ruurda et al. [20] & Cholecystectomy & Laparoscopy & $10 / 10$ & Longer setup times for robotics \\
\hline Heemskerk et al. [21] & Cholecystectomy & Laparoscopy & $11 / 11$ & $\begin{array}{l}\text { Less physical stress and mental strain for the } \\
\text { surgeon with robotics }\end{array}$ \\
\hline Baik et al. [22] & $\begin{array}{l}\text { Tumor specific } \\
\text { mesorectalexision }\end{array}$ & Laparoscopy & $18 / 18$ & Longer length of stay for robotics \\
\hline Jimenez et al. [23] & $\begin{array}{l}\text { Total or subtotal mesorectal } \\
\text { excision }\end{array}$ & Laparoscopy & $28 / 28$ & $\begin{array}{l}\text { Greater distal margins, longer setup time, } \\
\text { longer OR time for robotics }\end{array}$ \\
\hline Park et al. [24] & Right colectomies & Laparoscopy & $35 / 35$ & Longer OR time, higher costs for robotics \\
\hline Patriti et al. [25] & Total mesorectal excision & Laparoscopy & $29 / 37$ & Shorter OR time, fewer conversions \\
\hline Somashekar et al. [26] & $\begin{array}{l}\text { Rectal resection with total } \\
\text { mesorectal excision }\end{array}$ & Open Surgery & $25 / 25$ & $\begin{array}{l}\text { Greater distal margins, lower estimated blood } \\
\text { loss, shorter length of stay, longer OR time } \\
\text { for robotics }\end{array}$ \\
\hline
\end{tabular}

\section{Foregut surgery}

Robotic fundoplication has been adopted as an early application of da Vinci in general surgery, and a variety of publications demonstrate the safety and general feasibility of the robotic version of this procedure [27, 28]. Four randomized controlled trials of limited quality comparing robotic to laparoscopic Nissen fundoplication can be found in the up-to-date literature [15-18]. While all of these RTCs showed similar short-term clinical outcomes, one publication reported shorter operating room (OR) times for robotics [15] and another observed longer OR times [18]. Three RTCs demonstrated higher costs for the robotic procedure when compared to laparoscopy $[15,17,18]$. As such, several meta-analyses using different literature as the basis for calculations conclude that robotic Nissen fundoplication results in similar clinical outcomes when compared to the laparoscopic procedure [29-31], but OR times are longer [29] and costs are higher [29, 31].

While no RTCs that evaluates robotic Heller myotomy can be found, several comparison studies showed a perforation rate of $0 \%$ for the robotic patients with otherwise comparable clinical outcomes [32-34]. One study observed higher quality of life after robotic Heller myotomy when compared to conventional laparoscopy [33]. As such, a meta-analysis by Maeso et al. concluded that robotic Heller myotomy appears to result in fewer perforations and higher postoperative quality of life when compared to laparoscopy [30].
Several reports can be found in the robotic application for early gastric cancer with similar indications as for a laparoscopic approach. While no RTCs exist comparing robotic gastrectomy with alternative methods, several meta-analyses using lower-level-of-evidence comparative studies analyze the value of robotics for gastrectomy [35-40]. Overall data suggest that robotic surgery for gastric cancer is safe and feasible and results in similar peri-operative outcomes when compared to conventional laparoscopy. It appears that operative time might be prolonged when using robotic technology $[35,36,38]$, but there might be an advantage in regards to length of stay and estimated blood loss for robotic gastrectomy [35, 36, 38-40]. In addition, it has been suggested that the technical specifications of robotic technology enable a minimally invasive approach to D-2 lymphadenectomy [41]. This procedure has been established as the gold standard of treatment, with improved long-term oncological outcomes for the patients when compared to a limited D-1 lymphadenectomy [42]. Overall, more systematic data are needed to verify this potentially very meaningful advantage of robotics over conventional laparoscopy.

\section{Bariatric surgery}

While bariatric surgery is currently predominantly performed by conventional laparoscopy, several distinct anatomical challenges often exist, including a thick abdominal wall, 
hepatomegaly, and increased amounts of intra-abdominal fat. As such, procedures are usually challenged by a limited workspace, reduced surgical dexterity, and limited dexterity during conventional laparoscopy. Literature from other fields of surgery indicates that robotics may facilitate surgery in the obese population [43, 44], and thus robotics might be of relevance in the field of bariatric surgery.

The largest volume of clinical publications on robotic use for bariatric indications can be found for Roux-en-Y gastric bypass (RYGB). Since early reports in 2003, multiple groups have published their clinical outcomes with a variety of surgical methods, including hybrid and total robotic approaches to RYGB. While some of the early articles reported challenges of the robotic technology, mainly around the absence of force feedback leading to bowel injuries [45], more recent comparative studies [46-48] as well as systematic reviews $[49,50]$ do offer some evidence supporting the potential clinical advantages of robotic RYGB surgery, particularly in regards to the quality of the gastro-jejunal anastomosis. As such, a metaanalysis by Markar et al. showed lower rates of gastrojejunal stricture with the robotic approach when compared to the laparoscopic approach [50]. This reduced stricture rate as well as potentially reduced rates of gastro-jejunal leaks [46, $51,52]$ can be explained by the different technique that is usually used for the formation of gastro-jejunal anastomosis during robotic gastric bypass: while most gastrojejunal anastomoses during conventional laparoscopy are formed by either a circular or a linear stapler, robotic technology enables a "hand-sutured" anastomosis which might result in enhanced clinical outcomes. In addition, the only RTC from the field of robotic bariatric surgery showed significantly shorter OR times for robotic gastric bypass during the surgeon's learning curve when compared to conventional laparoscopy [19].

While some clinical evidence exists for robotic gastric bypass, much less is evident for other bariatric procedures. Potential reasons might include the fact that some alternative procedures such as gastric sleeve resection and gastric banding are less challenging, and thus conventional laparoscopy is more feasible or that other procedures such as duodenal switch with bilipancreatic diversion is a relatively rare indication.

In that context, the value of a robotic approach to sleeve gastrectomy (SG) appears unclear at present; although the robotic approach may facilitate the mobilization of the stomach and enable suturing of the previously stapled tissue, the most critical element of this procedure remains the formation of the gastric sleeve using staplers. Although robotic staplers for the da Vinci system have recently been released in limited geographies, no systematic data can be found for their application of gastric sleeve resections so far. Further experience with the robotic staplers will show whether this procedure might gain significance as a robotic approach. To date, literature consisting only low-level-of-evidence studies indicates general feasibility and safety with potentially prolonged operative times [53, 54]. One research group analyzed their series of robotic-assisted SGs and compared data to a systematic review of laparoscopic sleeve gastrectomies (LSG). This analysis showed lower leak and stricture rates with the robotic approach to SG [55].

Similarly, the clinical evidence for robotic installation of adjustable gastric band (AGB) is limited as few low-levelof-evidence studies can be found. Since the first report of a robotic placement of an AGB by Cadiere and Himpens in 1998 [4], other authors have reported on the feasibility and safety of performing robotic AGB placement [56, 57]. Although it seems apparent that robotic technology might provide advantages during some parts of the dissection and suturing the anterior gastric plication, the lack of tactile feedback may be a disadvantage during the preparation of the posterior gastric tunnel. However, the most significant barrier for robotics for this indication might be the limited technical challenge that is posed. Thus, robotics might only provide limited incremental value over conventional laparoscopy with at least currently increased costs.

Finally, biliopancreatic diversion with duodenal switch (BPD/DS) and revisional surgery (RS) have been reported to be feasible using the da Vinci surgical system [58-60]. While both procedures are of advanced complexity where robotics might potentially impact clinical outcomes positively, a very limited number of low-level-of-evidence studies can be found in the literature. Due to its limited application and the extensive need for multi-quadrant access, BPD/DS will most likely not develop into a dominating robotic indication with the currently existing robotic systems. However, revisional surgery is currently significantly increasing in terms of case numbers in the first world, and some reports can be found in the literature $[59,60]$. In addition, with the complexity of these procedures, a robotic approach appears to be a suitable option. As such, it can be estimated that the body of evidence in regards to robotic RS will increase over the next few years to allow a definite statement in the future.

\section{Hepatobiliary and transplant surgery}

With some evaluations of case-matched or randomized design comparing robotic multiport cholecystectomy with conventional laparoscopy showing similar clinical outcomes with increased costs and longer setup times for robotics, the routine clinical application of robotics for simple cholecystectomy appears limited [20, 61]. Still recently, it seems that the technique of multiport robotic cholecystectomy has been used in increasing numbers, and some reports that describe cholecystectomy as a procedure suitable to train residents on the da Vinci surgical system or for cases of advanced difficulty can be found [62-65]. A recent RTC has also showed that physical stress and mental strain might be reduced for the surgeon 
when cholecystectomy is performed using the da Vinci system in comparison to conventional laparoscopy [21]. More data in regards to single-site cholecystectomy are described below.

A number of reports from the field of robotic liver and pancreas surgery can be found; however, all studies are of limited quality at this point. So far, literature suggests the general feasibility of robotics for all common pancreatic resections including distal, central, and total pancreatectomy as well as for pancreaticoduodenectomy. Some potential shortterm advantages over open surgery and conventional laparoscopy might be confirmable with more systematic research in the future [66, 67]. Similarly, robotic liver resections have been reported to be safe and feasible when performed by experienced groups $[68,69]$. Overall, robotics appear promising in this field of advanced general surgery as this technology seems to have advantages that facilitate a variety of surgical maneuvers that are needed during liver resection. Still, more advanced robotic instrumentation will be needed to enable widespread application in the field of liver surgery.

While the robotic approach to donor nephrectomy has been described since the early years of robotics in general surgery [70-72], more advanced procedures from the field of robotic transplant surgery have only emerged in more recent years as a sign of progressive penetration of robotics into advanced areas of general surgery [73]. Described procedures include those on kidney, pancreas, and combined transplantations [74-77]. However, besides feasibility in very experienced hands, no firm evidenced-based conclusions can be drawn at this rather early point in the adoption curve.

\section{Colorectal surgery}

A good number of publications - mostly with limited quality though — can be found for robotic application in colorectal surgery, and general feasibility of robotics in colon surgery can be assumed $[78,79]$. While the technical advantages of robotics could play a role during more complex maneuvers, including extended lymphadenectomy and the formation of intra-corporeal anastomoses [80-82], more substantial clinical evidence is needed to clearly define the role of robotic technology for colon surgery. So far, a single RTC in regards to right colectomy showed longer OR times and higher costs for the robotic technique [24].

A greater body of evidence can be found for the application of robotics in rectal surgery, particularly regarding the treatment of rectal cancer. A RTC of robotic rectal resection versus open surgery has shown greater distal margins and significantly lower blood loss with the robotic technique [26]. Conventional laparoscopy has been described as a safe and effective alternative to the open approach, but relatively high rates of conversions and circumferential margin positivity have been the results of systematic research [83-85]. Therefore, the laparoscopic approach has not yet been established as the gold standard approach for patients with rectal cancer $[9,86]$. The technical superiority of robotics holds the promise to overcome the limitations of conventional laparoscopy in this setting and may result in fewer conversions and reduced rates of positive margins when compared to conventional laparoscopy [22, 87-90]. Some RTCs from this field also showed greater distal resection margins, fewer conversions, lower estimated blood loss, shorter length of stay, either shorter or longer OR times, and longer setup time for the robotic technique $[23,25,91]$. However, despite the fact that these studies are of randomized control design, the number of subjects is limited, and long-term outcomes are outstanding. Therefore, more systematic research of the field of robotics for rectal cancer is currently underway and first results are expected in the near future [87].

As a relatively novel and highly interesting procedure, robotic transanal resection of low-risk rectal cancers and benign conditions has recently been developed. Several research groups have published their laboratory experience as well as initial clinical experience of transanal robotic surgery (Fig. 3) for local excisions and retrograde total mesorectal excision $[92,93]$.

\section{Special da Vinci platforms}

Earliest reports of robotic single-site surgery (Fig. 4) encompass experiences with robotic surgery using multiport da Vinci instruments docked through a single incision with robotic instruments placed in unconventional arrangements [94]. Later, a dedicated set of semi-rigid instruments and curved cannulae for robotic single-site surgery was released in 2011 [95]. This platform was pre-dominantly used for cholecystectomy. Literature shows the general safety and feasibility of the technique with potentially shorter OR times and facilitated learning curves when compared to conventional single-incision laparoscopy [96, 97]. Several reports can be found on the application of robotic single-site surgery for other procedures [98]. Recently, an articulated needle holder was developed for the use with the robotic single-site platform to facilitate

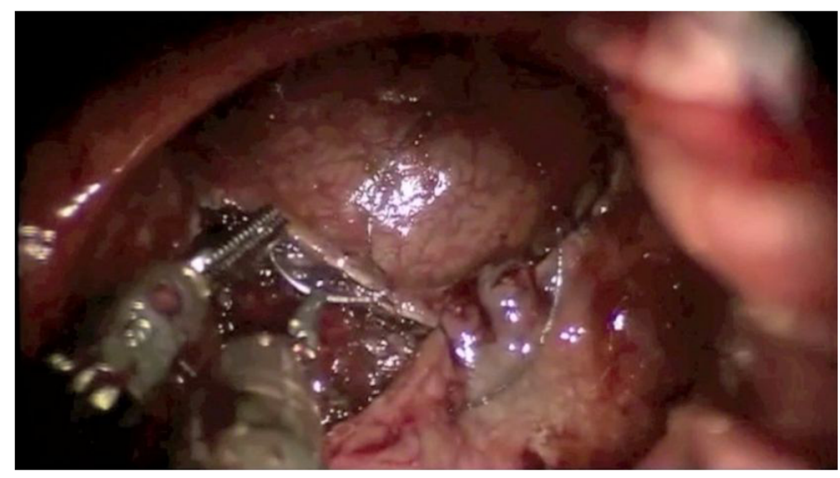

Fig. 3 da Vinci transanal surgery 


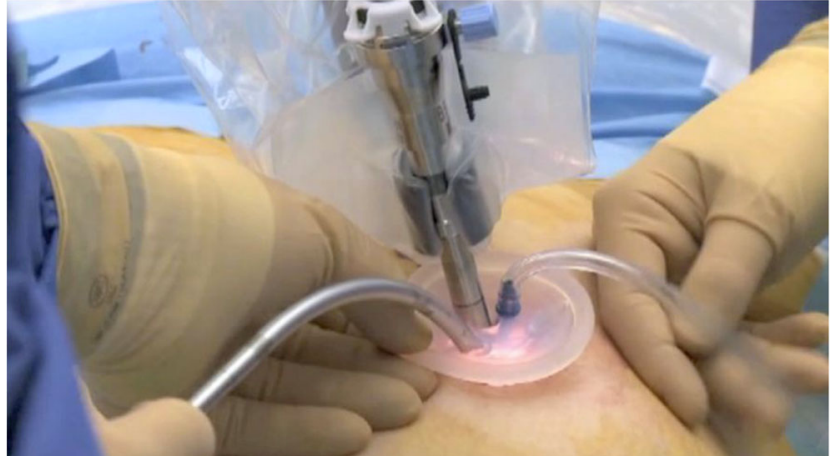

Fig. 4 da Vinci single-site cholecystectomy

suturing, but literature is still outstanding in regards to its potentially clinical value.

Another addition to the da Vinci Si technology has been the development of an intra-operative near-infrared fluorescence imaging system. This technology has been used during a variety of surgical procedures to visualize blood flow (Fig. 5), lymph node mapping, and intra-operative cholangiography and to identify the anatomy of the surgical field [99-101]. Systematic research will be needed to determine the impact of this technology on clinical outcomes.

\section{Summary of literature review}

Reflecting upon this literature review of robotics for general surgery, it becomes obvious that there is a serious lack of evidence for the clinical value of robotics in general surgery: a limited number of studies are of the highest level of evidence, but often of limited quality. Shortcomings include small patient cohorts, room for various sources of bias, and lack of long-term outcomes. As such, meta-analyses are also of limited robustness, and it remains unclear if the undisputed technical advantages of the da Vinci surgical system over conventional laparoscopy result in a clinical advance for the patient. Several reasons are worth discussing in that context: first, robotics is still at its infancy at the current point in time.

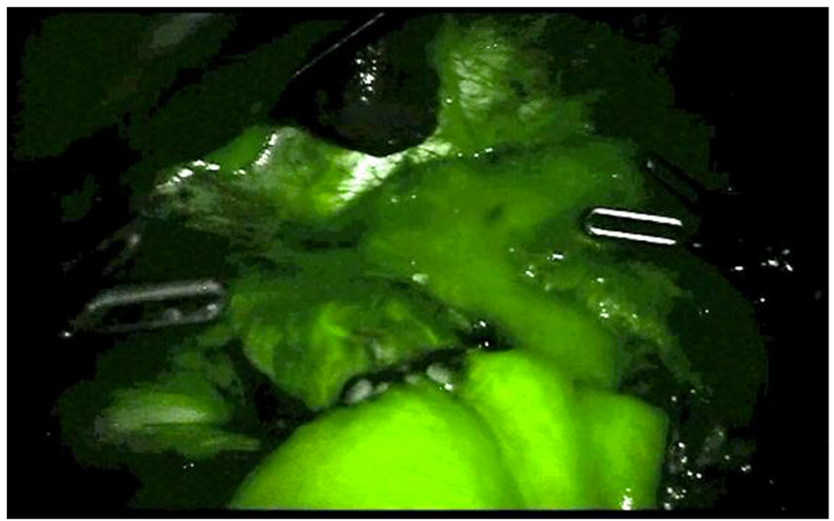

Fig. 5 da Vinci fluorescence imaging of gastric pouch during gastric bypass
It has been less than two decades since the first robotic general surgery procedure was performed. As such, many potentially very interesting indications of robotics in advanced general surgery - mainly where laparoscopy is not applicable due to its technical challenges - have not fully been explored yet. Creating significant clinical evidence takes time and a natural "publication curve" from lowest level of evidence studies such as case reports to high-quality randomized trials, and meta-analyses have to be taken into consideration. While lower level of evidence research clearly indicates a potential clinical value of the robotic technology, there are serious barriers for the conduct of randomized controlled trial including organizational challenges and costs. At the present point in time, the robotic market appears to be not yet saturated as procedure numbers are rising despite this lack of clear clinical evidence. As such, there does not seem to be enough "pressure" for delivering concrete data in regards to clinical and cost effectiveness of robotic technology. However, besides academic interest, global challenges in the health market including increasing economic challenges will drive further research in the field of robotics for general surgery. Thus, several high-quality trials comparing robotic technology to either open or laparoscopic surgery are on their way, and their results are awaited with great anticipation $[87,102]$.

\section{Perspective of robotic general surgery}

Despite the currently limited proof of the clinical and cost effectiveness of robotics for general surgery, the robotic technology clearly holds the promise of revolutionizing conventional general surgery - ultimately for the benefit of many patients to come.

On one hand, the currently most commonly used da Vinci surgical system is subject to constant improvements including the recent release of a novel version that promises to facilitate multi-quadrant surgery, the addition of new instruments, and the augmentation of functions by integration of novel technologies such as enhanced vision and many others. While many new technologies are also developed for open and laparoscopic surgery, the possibility of seamless integration into one surgical tool is only possible when a computer is the central element of surgical care - such as a robot. In addition, a variety of other robotic surgical systems are being developed at present and brought to clinical applications in the near future.

Some are console-cart systems with an operator seated at a console and instrument carts, which will create direct competition for the da Vinci. These systems share many of the essential features of the da Vinci surgical system and may be subject to intellectual disputes such as previous systems before potentially entering the market. For all of these systems, the surgeon works at a control console, observes video feeds of the operating field, and remotely controls end-effectors that 
are installed in or around the patient who is placed in a sterile field in the operating room. A common challenge of consolecart systems appears to be the setup process that is required for the correct installation and the costs for the hardware and software as well as for the reposable instrumentation. On the other hand, these systems are most capable to deliver intuitive control, as well as the capability to enable tele-surgery and tele-mentoring.

While none of such console-cart systems besides the da Vinci surgical system has yet been released for widespread commercial distribution, several products are anticipated to be available soon. Each of them offers distinct features that promise to improve the existing technology and thus hopes to conquer a piece of the surgical market by providing superior patient outcomes and/or reduced costs.

A frequent criticism about the da Vinci system is the absence of tactile feedback for the surgeon, which can lead to unexpected strain on tissue and inadvertent injuries. This lack has created an avenue for new development: The University of Pennsylvania is currently developing a product called "Verro Touch" which will be capable to add haptic capabilities to the da Vinci surgical system by providing tactile and auditory feedback to a da Vinci operator based on instrument vibration [103].

The Telelap ALF-X system is a novel telesurgical system developed by SOFAR s.p.a. in. Its design consists of a fourarm system with innovative tactile sensing capabilities. The company claims to streamline the robotic surgical experience by improving safety, providing natural perception, ease of use, and cost effectiveness (ALF-X T. wwwalf-xcom).

The DLR MIRO is a modular system of robotic arms being developed by the Institute of Robotics and Mechtronics in Germany. The MIRO is a multi-jointed surgical arm that can be used alone or in groups to perform a wide variety of surgical tasks. Thus, a single MIRO might be used in conjunction with a human surgeon to perform specific visualization or manipulation tasks (DLR, http://www.dlrde/rmc/rm-neu/en/ desktopdefaultaspx/tabid-3828/).

Titan Medical Inc. in Canada is developing the SPORT ${ }^{\mathrm{TM}}$ (Single Port Orifice Robotic Technology), which is a system for use in minimally invasive surgery. The SPORT ${ }^{\mathrm{TM}}$ is a single-port robotic platform that includes a 3-D vision system, articulated instruments, and a surgeon workstation. Similarly to the da Vinci surgical system, it offers an interface to the robotic platform for controlling the instruments and providing a 3D endoscopic view of the surgical field. The company aims to expand the use of robotics to currently underserved surgical areas, and commercialization is currently expected for 2017 (Inc. TM. wwwtitanmedicalinccom).

Besides these emerging console-cart systems, direct image-guided robots might be of relevance for the field of general surgery in the future. In these kinds of systems, the movements are not directly controlled by a surgeon, but rather directly by a computer to precisely fit certain constraints determined by imaging. Therefore, these systems are not considered master-slave systems and might be closer to the natural perception of a "robot" than currently available systems for general surgery. Considering the complexity of soft tissue surgery, these systems are mainly for relatively simple and very specific surgical subtasks during which close tolerance is desirable and can also be considered as "smart power tools".

Examples of such systems include the Cyberknife which was approved by the FDA for human use in 2001 for delivering precision dosages of radiation to tissue. Using imaging data, the Cyberknife radiates a specific site from multiple angles, which reduces the effect on the surrounding tissue while maximizing dosage in the desired area. Since its introduction to the market, the Cyberknife has been used on a wide variety of tumors in locations throughout the body [104-106]. Other direct image-guided robots include the SpineAssist by Mazor Robotics and the Robotic Arm Interactive Orthopedic System (RIO) by MAKO Surgical Corp; both systems currently target orthopedic procedures as soft tissue deformation remains a serious constraint for the use of these kinds of robots for the field of general surgery. Recent developments of novel direct image-guided robots that might be applicable to procedures of general surgery are aimed to use magnetic resonance imaging to guide access to specific regions. However, no such robotic systems have been approved to date.

In addition, miniaturized surgical robots are being developed as a true quantum leap in surgical technology in the future. These systems are designed as small autonomous or remotely controlled robots capable of operating within the patient's body. These kinds of robots would be of particular use in constraint spaces with challenging accesses. The currently available PillCam series from Given Imaging, which is mainly used as an alternative to conventional endoscopy, is subject of such research and technological advance that it promises to soon have the possibility of external control. With this capability, a more active interventional role is possible if other miniaturized systems like electrocautery tips, biopsy forceps, or pharmaceutical dispensers are included in the design. Various other miniaturized robotic systems under development include the Heartlander by the Robotics Institute of Carnegie Mellon University, which uses an inchworm-like locomotion system to gently move around on the epicardia, and a microrobot by the Hanyang University in Seoul that crawls inside blood vessels to address occlusive disease. Despite the fact that these systems are still early in their development, it appears evident that the field of robotics offers unlimited opportunities for the future.

\section{Conclusion}

Besides the current absence of significant clinical evidence of robotics in general surgery, it seems obvious that robotics hold 
the promise to continuously revolutionize the field of general surgery. While clinical evidence will continue to evolve with time, currently available systems are being subject to constant improvement and augmentation with additional technology that is essentially only enabled by having a computer as the central element of surgical care. In addition, new systems are under development, and their commercialization will further shape the landscape of surgical robotics.

Conflicts of interest Monika Hagen is a part-time employee of Intuitive Surgical Inc.

\section{References}

1. Davis CJ (1992) A history of endoscopic surgery. Surg Laparosc Endosc 2(1):16-23

2. Bhattacharya K (2007) Kurt Semm: A laparoscopic crusader. J Minim Access Surg 3(1):35-36

3. Fisher SSMM, Humphries J et al (1986) Virtual environment display system. In: Crow F, Pizer S (eds) Proceedings of the workshop on interactive 3-dimensional graphics. AMC, New York, pp 1-12

4. Cadiere GB, Himpens J, Vertruyen M, Favretti F (1999) The world's first obesity surgery performed by a surgeon at a distance. Obes Surg 9(2):206-209

5. Baek SJ, Kim SH (2014) Robotics in general surgery: an evidencebased review. Asian J Endosc Surg 7(2):117-123

6. Augustin F, Bodner J, Wykypiel H, Schwinghammer C, Schmid T (2012) Perioperative results of robotic lung lobectomy: summary of literature. Surg Endosc 26(4):1190-1191

7. Genden EM, O'Malley BW Jr, Weinstein GS, Stucken CL, Selber JC, Rinaldo A et al (2012) Transoral robotic surgery: role in the management of upper aerodigestive tract tumors. Head Neck 34(6):886-893

8. Halabi WJ, Jafari MD, Nguyen VQ, Carmichael JC, Mills S, Stamos MJ et al (2013) A nationwide analysis of the use and outcomes of epidural analgesia in open colorectal surgery. J Gastrointest Surg 17(6):1130-1137

9. Pox C, Aretz S, Bischoff SC, Graeven U, Hass M, Heussner P et al (2013) S3-guideline colorectal cancer version 1.0. Z Gastroenterol 51(8):753-854

10. Kang CY, Halabi WJ, Chaudhry OO, Nguyen V, Ketana N, Carmichael JC et al (2013) A nationwide analysis of laparoscopy in high-risk colorectal surgery patients. J Gastrointest Surg 17(2): 382-391

11. (DGU) DGfU (2011) Interdisziplinäre Leitlinie der Qualität S3 zur Früherkennung, Diagnose und Therapie der verschiedenen Stadien des Prostatakarzinoms Version 1.03 - Mär

12. Novara G, Ficarra V, Rosen RC, Artibani W, Costello A, Eastham JA et al (2012) Systematic review and meta-analysis of perioperative outcomes and complications after robot-assisted radical prostatectomy. Eur Urol 62(3):431-452

13. Ficarra V, Novara G, Rosen RC, Artibani W, Carroll PR, Costello A et al (2012) Systematic review and meta-analysis of studies reporting urinary continence recovery after robot-assisted radical prostatectomy. Eur Urol 62(3):405-417

14. Ficarra V, Sooriakumaran P, Novara G, Schatloff O, Briganti A, Van der Poel H et al (2012) Systematic review of methods for reporting combined outcomes after radical prostatectomy and proposal of a novel system: the survival, continence, and potency (SCP) classification. Eur Urol 61(3):541-548
15. Muller-Stich BP, Reiter MA, Wente MN, Bintintan VV, Koninger J, Buchler MW et al (2007) Robot-assisted versus conventional laparoscopic fundoplication: short-term outcome of a pilot randomized controlled trial. Surg Endosc 21(10):1800-1805

16. Draaisma WA, Ruurda JP, Scheffer RC, Simmermacher RK, Gooszen HG, Rijnhart-de Jong HG et al (2006) Randomized clinical trial of standard laparoscopic versus robot-assisted laparoscopic Nissen fundoplication for gastro-oesophageal reflux disease. Br J Surg 93(11):1351-1359

17. Morino M, Pellegrino L, Giaccone C, Garrone C, Rebecchi F (2006) Randomized clinical trial of robot-assisted versus laparoscopic Nissen fundoplication. Br J Surg 93(5):553-558

18. Nakadi IE, Melot C, Closset J, DeMoor V, Betroune K, Feron P et al (2006) Evaluation of da Vinci Nissen fundoplication clinical results and cost minimization. World J Surg 30(6):1050-1054

19. Sanchez BR, Mohr CJ, Morton JM, Safadi BY, Alami RS, Curet MJ (2005) Comparison of totally robotic laparoscopic Roux-en-Y gastric bypass and traditional laparoscopic Roux-en-Y gastric bypass. Surg Obes Relat Dis 1(6):549-554

20. Ruurda JP, Visser PL, Broeders IA (2003) Analysis of procedure time in robot-assisted surgery: comparative study in laparoscopic cholecystectomy. Comput Aided Surg 8(1):24-29

21. Heemskerk J, Zandbergen HR, Keet SW, Martijnse I, van Montfort G, Peters RJ et al (2014) Relax, it's just laparoscopy! A prospective randomized trial on heart rate variability of the surgeon in robotassisted versus conventional laparoscopic cholecystectomy. Dig Surg 31(3):225-232

22. Baik SH, Kwon HY, Kim JS, Hur H, Sohn SK, Cho CH et al (2009) Robotic versus laparoscopic low anterior resection of rectal cancer: short-term outcome of a prospective comparative study. Ann Surg Oncol 16(6):1480-1487

23. Jimenez Rodriguez RM DPJ, de La Portillade Juan F, Prendes Sillero E, MArie Hisnard Cadet Dussort J, Padillo J (2011) Prospective randomised study: robotic-assisted versus conventional laparoscopic surgery in colorectal cancer resection. Cirurgie Espanola 89(7):432-438

24. Park JS, Choi GS, Park SY, Kim HJ, Ryuk JP (2012) Randomized clinical trial of robot-assisted versus standard laparoscopic right colectomy. Br J Surg 99(9):1219-1226

25. Patriti A, Ceccarelli G, Bartoli A, Spaziani A, Biancafarina A, Casciola L (2009) Short- and medium-term outcome of robotassisted and traditional laparoscopic rectal resection. JSLS 13(2): 176-183

26. Somashekhar SP AK, Rajashekhar J, Zaveri S (2013) Prospective randomized study comparing robotic-assisted surgery with traditional laparotomy for rectal cancer-Indian study. Indian J Surg; Published online 11 November

27. Heemskerk J, van Gemert WG, Greve JW, Bouvy ND (2007) Robot-assisted versus conventional laparoscopic Nissen fundoplication: a comparative retrospective study on costs and time consumption. Surg Laparosc Endosc Percutan Tech 17(1):1-4

28. Hagen ME, Inan I, Pugin F, Morel P (2007) [The da Vinci surgical system in digestive surgery]. Rev Med Suisse 27(117):1622-1626

29. Markar SR, Karthikesalingam AP, Hagen ME, Talamini M, Horgan S, Wagner OJ (2010) Robotic vs. laparoscopic Nissen fundoplication for gastro-oesophageal reflux disease: systematic review and meta-analysis. Int J Med Robot 6(2):125-131

30. Maeso S, Reza M, Mayol JA, Blasco JA, Guerra M, Andradas E et al (2010) Efficacy of the Da Vinci surgical system in abdominal surgery compared with that of laparoscopy: a systematic review and meta-analysis. Ann Surg 252(2):254-262

31. Wang Z, Zheng Q, Jin Z (2012) Meta-analysis of robot-assisted versus conventional laparoscopic Nissen fundoplication for gastrooesophageal reflux disease. ANZ J Surg 82(3):112-117

32. Horgan S, Galvani C, Gorodner MV, Omelanczuck P, Elli F, Moser F et al (2005) Robotic-assisted Heller myotomy versus laparoscopic 
Heller myotomy for the treatment of esophageal achalasia: multicenter study. J Gastrointest Surg 9(8):1020-1029, discussion 9-30

33. Huffmanm LC, Pandalai PK, Boulton BJ, James L, Starnes SL, Reed MF et al (2007) Robotic Heller myotomy: a safe operation with higher postoperative quality-of-life indices. Surgery 142(4): 613-618, discussion 8-20

34. Iqbal A, Haider M, Desai K, Garg N, Kavan J, Mittal S et al (2006) Technique and follow-up of minimally invasive Heller myotomy for achalasia. Surg Endosc 20(3):394-401

35. Marano A, Choi YY, Hyung WJ, Kim YM, Kim J, Noh SH (2013) Robotic versus laparoscopic versus open gastrectomy: a meta-analysis. J Gastric Cancer 13(3):136-148

36. Liao G, Chen J, Ren C, Li R, Du S, Xie G et al (2013) Robotic versus open gastrectomy for gastric cancer: a meta-analysis. PLoS One 8(12):e81946

37. Liao GX, Xie GZ, Li R, Zhao ZH, Sun QQ, Du SS et al (2013) Meta-analysis of outcomes compared between robotic and laparoscopic gastrectomy for gastric cancer. Asian Pac J Cancer Prev 14(8):4871-4875

38. Hyun MH, Lee CH, Kim HJ, Tong Y, Park SS (2013) Systematic review and meta-analysis of robotic surgery compared with conventional laparoscopic and open resections for gastric carcinoma. Br J Surg 100(12):1566-1578

39. Shen WS, Xi HQ, Chen L, Wei B (2014) A meta-analysis of robotic versus laparoscopic gastrectomy for gastric cancer. Surg Endosc 28(10):2795-2802

40. Xiong B, Ma L, Zhang C (2012) Robotic versus laparoscopic gastrectomy for gastric cancer: a meta-analysis of short outcomes. Surg Oncol 21(4):274-280

41. D'Annibale A, Pende V, Pernazza G, Monsellato I, Mazzocchi P, Lucandri G et al (2011) Full robotic gastrectomy with extended (D2) lymphadenectomy for gastric cancer: surgical technique and preliminary results. J Surg Res 166(2):e113-e120

42. Songun I, Putter H, Kranenbarg EM, Sasako M, van de Velde CJ (2010) Surgical treatment of gastric cancer: 15-year follow-up results of the randomised nationwide Dutch D1D2 trial. Lancet Oncol 11(5):439-449

43. Gallo T, Kashani S, Patel DA, Elsahwi K, Silasi DA, Azodi M (2012) Robotic-assisted laparoscopic hysterectomy: outcomes in obese and morbidly obese patients. JSLS 16(3):421-427

44. Hemli JM, Darla LS, Panetta CR, Jennings J, Subramanian VA, Patel NC (2012) Does body mass index affect outcomes in robotic-assisted coronary artery bypass procedures? Innovations (Phila) 7(5):350-353

45. Hubens G, Balliu L, Ruppert M, Gypen B, Van Tu T, Vaneerdeweg W (2008) Roux-en-Y gastric bypass procedure performed with the da Vinci robot system: is it worth it? Surg Endosc 22(7):1690-1696

46. Hagen ME, Pugin F, Chassot G, Huber O, Buchs N, Iranmanesh P, et al (2011) Reducing cost of surgery by avoiding complications: the model of robotic Roux-en-y gastric bypass. Obes Surg

47. Ayloo SM, Addeo P, Buchs NC, Shah G, Giulianotti PC (2011) Robot-assisted versus laparoscopic Roux-en-Y gastric bypass: is there a difference in outcomes? World J Surg 35(3):637-642

48. Park CW, Lam EC, Walsh TM, Karimoto M, Ma AT, Koo M et al (2011) Robotic-assisted Roux-en-Y gastric bypass performed in a community hospital setting: the future of bariatric surgery? Surg Endosc 25(10):3312-3321

49. Fourman MM, Saber AA (2012) Robotic bariatric surgery: a systematic review. Surg Obes Relat Dis 8(4):483-488

50. Markar SR, Karthikesalingam AP, Venkat-Ramen V, Kinross J, Ziprin P (2011) Robotic vs. laparoscopic Roux-en-Y gastric bypass in morbidly obese patients: systematic review and pooled analysis. Int J Med Robot 7(4):393-400

51. Tieu K, Allison N, Snyder B, Wilson T, Toder M, Wilson E (2013) Robotic-assisted Roux-en-Y gastric bypass: update from 2 highvolume centers. Surg Obes Relat Dis 9(2):284-288
52. Buchs NC, Morel P, Azagury DE, Jung M, Chassot G, Huber O et al (2014) Laparoscopic versus robotic Roux-en-Y gastric bypass: lessons and long-term follow-up learned from a large prospective monocentric study. Obes Surg 24(12):2031-2039

53. Ayloo S, Buchs NC, Addeo P, Bianco FM, Giulianotti PC (2011) Robot-assisted sleeve gastrectomy for super-morbidly obese patients. J Laparoendosc Adv Surg Tech A 21(4):295-299

54. Diamantis T, Alexandrou A, Nikiteas N, Giannopoulos A, Papalambros E (2011) Initial experience with robotic sleeve gastrectomy for morbid obesity. Obes Surg 21(8):1172-1179

55. Romero RJ, Kosanovic R, Rabaza JR, Seetharamaiah R, Donkor C, Gallas M et al (2013) Robotic sleeve gastrectomy: experience of 134 cases and comparison with a systematic review of the laparoscopic approach. Obes Surg 23(11):1743-1752

56. Muhlmann G, Klaus A, Kirchmayr W, Wykypiel H, Unger A, Holler E et al (2003) DaVinci robotic-assisted laparoscopic bariatric surgery: is it justified in a routine setting? Obes Surg 13(6):848-854

57. Edelson PK, Dumon KR, Sonnad SS, Shafi BM, Williams NN (2011) Robotic vs. conventional laparoscopic gastric banding: a comparison of 407 cases. Surg Endosc 25(5):1402-1408

58. Sudan R, Puri V, Sudan D (2007) Robotically assisted biliary pancreatic diversion with a duodenal switch: a new technique. Surg Endosc 21(5):729-733

59. Ayloo SM, Choudhury N (2014) Robotic revisional bariatric surgery: single-surgeon case series. Int J Med Robot

60. Buchs NC, Pugin F, Azagury DE, Huber O, Chassot G, Morel P (2014) Robotic revisional bariatric surgery: a comparative study with laparoscopic and open surgery. Int J Med Robot 10(2):213217

61. Breitenstein S, Nocito A, Puhan M, Held U, Weber M, Clavien PA (2008) Robotic-assisted versus laparoscopic cholecystectomy: outcome and cost analyses of a case-matched control study. Ann Surg 247(6):987-993

62. Rosemurgy A, Ryan C, Klein R, Sukharamwala P, Wood T, Ross S (2014) Does the cost of robotic cholecystectomy translate to a financial burden? Surg Endosc

63. Ayloo S, Roh Y, Choudhury N (2014) Robotic cholecystectomy: training of residents in use of the robotic platform. Int J Med Robot 10(1):88-92

64. Ayloo S, Roh Y, Choudhury N (2014) Laparoscopic versus robotassisted cholecystectomy: a retrospective cohort study. Int J Surg 12(10):1077-1081

65. Nelson EC, Gottlieb AH, Muller HG, Smith W, Ali MR, Vidovszky TJ (2014) Robotic cholecystectomy and resident education: the UC Davis experience. Int J Med Robot 10(2):218-222

66. Giulianotti PC, Addeo P, Buchs NC, Ayloo SM, Bianco FM (2011) Robotic extended pancreatectomy with vascular resection for locally advanced pancreatic tumors. Pancreas 40(8):1264-1270

67. Giulianotti PC, Addeo P, Buchs NC, Bianco FM, Ayloo SM (2011) Early experience with robotic total pancreatectomy. Pancreas 40(2): 311-313

68. Giulianotti PC, Coratti A, Sbrana F, Addeo P, Bianco FM, Buchs $\mathrm{NC}$ et al (2011) Robotic liver surgery: results for 70 resections. Surgery 149(1):29-39

69. Buchs NC, Oldani G, Orci LA, Majno PE, Mentha G, Morel P et al (2014) Current status of robotic liver resection: a systematic review. Expert Rev Anticancer Ther 14(2):237-246

70. Horgan S, Vanuno D, Benedetti E (2002) Early experience with robotically assisted laparoscopic donor nephrectomy. Surg Laparosc Endosc Percutan Tech 12(1):64-70

71. Horgan S, Galvani C, Gorodner MV, Jacobsen GR, Moser F, Manzelli A et al (2007) Effect of robotic assistance on the "learning curve" for laparoscopic hand-assisted donor nephrectomy. Surg Endosc 21(9):1512-1517 
72. Oberholzer J, Testa G, Sankary H, John E, Thielke J, Benedetti E (2004) Kidney transplantation at the University of Illinois at Chicago from 1988-2004. Clin Transpl :143-9

73. Hagen ME, Joliat C, Buchs JB, Nastasi A, Ruttimann R, Lazeyras F et al (2014) [Robotic-assisted organ transplantation]. Rev Med Suisse 10(435):1356-1360

74. Tzvetanov I, D'Amico G, Bejarano-Pineda L, Benedetti E (2014) Robotic-assisted pancreas transplantation: where are we today? Curr Opin Organ Transplant 19(1):80-82

75. Oberholzer J, Giulianotti P, Danielson KK, Spaggiari M, BejaranoPineda L, Bianco F et al (2013) Minimally invasive robotic kidney transplantation for obese patients previously denied access to transplantation. Am J Transplant 13(3):721-728

76. Boggi U, Vistoli F, Signori S, D'Imporzano S, Amorese G, Consani $\mathrm{G}$ et al (2011) Robotic renal transplantation: first European case. Transpl Int 24(2):213-218

77. Boggi U, Signori S, Vistoli F, Amorese G, Consani G, De Lio N et al (2011) Current perspectives on laparoscopic robot-assisted pancreas and pancreas-kidney transplantation. Rev Diabet Stud 8(1):28-34, Spring

78. Ballantyne GH, Ewing D, Pigazzi A, Wasielewski A (2006) Telerobotic-assisted laparoscopic right hemicolectomy: lateral to medial or medial to lateral dissection? Surg Laparosc Endosc Percutan Tech 16(6):406-410

79. Antoniou SA, Antoniou GA, Koch OO, Pointner R, Granderath FA (2012) Robot-assisted laparoscopic surgery of the colon and rectum. Surg Endosc 26(1):1-11

80. Buchs NC, Pugin F, Bucher P, Morel P (2011) Totally robotic right colectomy: a preliminary case series and an overview of the literature. Int J Med Robot

81. Trastulli S, Coratti A, Guarino S, Piagnerelli R, Annecchiarico M, Coratti F, et al (2014) Robotic right colectomy with intracorporeal anastomosis compared with laparoscopic right colectomy with extracorporeal and intracorporeal anastomosis: a retrospective multicentre study. Surg Endosc

82. Trastulli S, Desiderio J, Farinacci F, Ricci F, Listorti C, Cirocchi R et al (2013) Robotic right colectomy for cancer with intracorporeal anastomosis: short-term outcomes from a single institution. Int J Colorectal Dis 28(6):807-814

83. Agha A, Benseler V, Hornung M, Gerken M, Iesalnieks I, Furst A et al (2014) Long-term oncologic outcome after laparoscopic surgery for rectal cancer. Surg Endosc 28(4):1119-1125

84. Dulucq JL, Wintringer P, Stabilini C, Mahajna A (2005) Laparoscopic rectal resection with anal sphincter preservation for rectal cancer: long-term outcome. Surg Endosc 19(11):1468-1474

85. Guillou PJ, Quirke P, Thorpe H, Walker J, Jayne DG, Smith AM et al (2005) Short-term endpoints of conventional versus laparoscopic-assisted surgery in patients with colorectal cancer (MRC CLASICC trial): multicentre, randomised controlled trial. Lancet 365(9472):1718-1726

86. Row D, Weiser MR (2010) An update on laparoscopic resection for rectal cancer. Cancer Control 17(1):16-24

87. Collinson FJ, Jayne DG, Pigazzi A, Tsang C, Barrie JM, Edlin R et al (2012) An international, multicentre, prospective, randomised, controlled, unblinded, parallel-group trial of robotic-assisted versus standard laparoscopic surgery for the curative treatment of rectal cancer. Int J Colorectal Dis 27(2):233-241

88. Halabi WJ, Kang CY, Jafari MD, Nguyen VQ, Carmichael JC, Mills S, et al (2013) Robotic-assisted colorectal surgery in the United States: a nationwide analysis of trends and outcomes. World J Surg

89. Baek SJ, Al-Asari S, Jeong DH, Hur H, Min BS, Baik SH et al (2013) Robotic versus laparoscopic coloanal anastomosis with or without intersphincteric resection for rectal cancer. Surg Endosc 27(11):4157-4163
90. Ielpo B, Caruso R, Quijano Y, Duran H, Diaz E, Fabra I et al (2014) Robotic versus laparoscopic rectal resection: is there any real difference? A comparative single center study. Int J Med Robot 10(3): 300-305

91. Baik SH, Ko YT, Kang CM, Lee WJ, Kim NK, Sohn SK et al (2008) Robotic tumor-specific mesorectal excision of rectal cancer: short-term outcome of a pilot randomized trial. Surg Endosc 22(7): 1601-1608

92. Buchs NC, Pugin F, Volonte F, Hagen ME, Morel P, Ris F (2013) Robotic transanal endoscopic microsurgery: technical details for the lateral approach. Dis Colon Rectum 56(10):1194-1198

93. Hompes R, Rauh SM, Hagen ME, Mortensen NJ (2012) Preclinical cadaveric study of transanal endoscopic da Vinci(R) surgery. Br J Surg 99(8):1144-1148

94. Hagen ME, Wagner OJ, Inan I, Morel P, Fasel J, Jacobsen G et al (2010) Robotic single-incision transabdominal and transvaginal surgery: initial experience with intersecting robotic arms. Int J Med Robot 6(3):251-255

95. Kroh M, El-Hayek K, Rosenblatt S, Chand B, Escobar P, Kaouk J et al (2011) First human surgery with a novel single-port robotic system: cholecystectomy using the da Vinci single-site platform. Surg Endosc 25(11):3566-3573

96. Morel P, Hagen ME, Bucher P, Buchs NC, Pugin F (2011) Robotic single-port cholecystectomy using a new platform: initial clinical experience. J Gastrointest Surg 15(12):2182-2186

97. Spinoglio G, Lenti LM, Maglione V, Lucido FS, Priora F, Bianchi $\mathrm{PP}$ et al (2012) Single-site robotic cholecystectomy (SSRC) versus single-incision laparoscopic cholecystectomy (SILC): comparison of learning curves. First Eur Experience Surg Endosc 26(6):1648 1655

98. Morelli L, Guadagni S, Caprili G, Candio GD, Boggi U, Mosca F (2013) Robotic right colectomy using the Da Vinci single-site (R) platform: case report. Int J Med Robot

99. Hellan M, Spinoglio G, Pigazzi A, Lagares-Garcia JA (2014) The influence of fluorescence imaging on the location of bowel transection during robotic left-sided colorectal surgery. Surg Endosc

100. Buchs NC, Hagen ME, Pugin F, Volonte F, Bucher P, Schiffer E, et al (2012) Intra-operative fluorescent cholangiography using indocyanin green during robotic single site cholecystectomy. Int J Med Robot

101. Holloway RW, Bravo RA, Rakowski JA, James JA, Jeppson CN, Ingersoll SB et al (2012) Detection of sentinel lymph nodes in patients with endometrial cancer undergoing robotic-assisted staging: a comparison of colorimetric and fluorescence imaging. Gynecol Oncol 126(1):25-29

102. van der Sluis PC, Ruurda JP, van der Horst S, Verhage RJ, Besselink MG, Prins MJ et al (2012) Robot-assisted minimally invasive thoraco-laparoscopic esophagectomy versus open transthoracic esophagectomy for resectable esophageal cancer, a randomized controlled trial (ROBOT trial). Trials 13:230

103. Kuchenbecker KJ, Gewirtz J, McMahan W, Standish D, Martin P, Bohren J, Mendoza PJ, Lee DI (2010) VerroTouch: high-frequency acceleration feedback for telerobotic surgery. In Proceedings, EuroHaptics, pp 189-196

104. Adler JR Jr, Chang SD, Murphy MJ, Doty J, Geis P, Hancock SL (1997) The Cyberknife: a frameless robotic system for radiosurgery. Stereotact Funct Neurosurg 69(1-4 Pt 2):124-128

105. Wowra B, Muacevic A, Tonn JC (2012) CyberKnife radiosurgery for brain metastases. Prog Neurol Surg 25:201-209

106. Muacevic A (2007) [Cyberknife radiosurgery: a new treatment method for image-guided and robot-assisted precision radiation]. MMW Fortschr Med 149(7):42-43, Das Cyberknife: Schmerzfreie Chirurgie der nachsten Generation. Strahlenmesser lasst inoperable Tumoren verschwinden. ger 